\title{
Change in morph frequency in the snail Cepaea nemoralis on the Marlborough Downs
}

\author{
L. M. COOK$^{*} \dagger$, ROBERT H. COWIE $\$ \oint$ \& J. S. JONES \\ $\dagger$ The Manchester Museum, University of Manchester, Manchester M13 9PL, U.K. and $\$$ Department of Genetics and \\ Biometry, University College London, 4 Stephenson Way, London NW1 2HE, U.K.
}

\begin{abstract}
Temporal change in morph frequency has been examined in Cepaea nemoralis (L.) from the Marlborough Downs, southern England, first studied by Cain and Currey and resurveyed after 25 years by Cowie and Jones. Three methods of estimating selective coefficients over a few generations have been applied to data on the frequency of brown at the shell colour locus, showing an average selective disadvantage of $3-6 \%$ per generation. The integration method overestimated selection, whereas the ratio method gave values close to those obtained by iteration. There is heterogeneity in response between samples, indicating a patchy distribution of morph frequency change, and evidence of homogenization of frequency over the period of the study. Both tendencies are also seen when banded vs. unbanded at the banding locus is examined. Possible reasons are discussed. Between-colony migration may be involved, at levels higher than usually assumed to prevail.
\end{abstract}

Keywords: Cepaea, frequency change, migration, selection, visual polymorphism.

\section{Introduction}

In 1960 and 1961, Cain \& Currey (1963a) surveyed morph frequencies in populations of the visually polymorphic land snails Cepaea nemoralis and C. hortensis on the Marlborough Downs in south-central England, including both woods and open downland sites. The locality of this survey is famous for having generated the concept of 'area effect', a term used by Cain and Currey to describe places where 'the predominance of a few morphs irrespective of habitat and background characterizes areas vastly larger than that of panmictic populations' (Cain \& Currey, 1963a). The area examined falls within a square approximately $8 \mathrm{~km}$ from $\mathrm{N}$ to $\mathrm{S}$ and $7 \mathrm{~km}$ from $\mathrm{W}$ to E. The brown morph, which is dominant over pink and yellow at the colour locus, was uncommon over most of the area, but brown snails occurred at a frequency of over $25 \%$ to the north (Barbury Castle) and up to $90 \%$ in samples in the southern third of the study area.

*Correspondence. E-mail: lcook@fs1.scg.man.ac.uk §Present address: Bishop Museum, 1525 Bernice Street, Honolulu, Hawaii 96817-0916, U.S.A.
In 1985 the area was resurveyed by Cowie \& Jones (1998). Some sites no longer had Cepaea present and at others the species composition had changed. The majority, however, permitted comparison of morph frequencies between the two surveys. The intention was to look for general trends in the data, which may be correlated with climatic change or with large-scale ecological changes such as the vegetational modifications that have followed the decline in rabbit populations in recent years (Murray \& Clarke, 1978; Cameron et al., 1980). Overall patterns of change were therefore examined, without special attention being paid to possible between-colony differences. In $C$. nemoralis there was no apparent change in frequency of the banded morphs over the intervening period, but a significant overall decrease in the frequency of browns. In $C$. hortensis the frequency of unbanded shells has increased and there has probably been a decline in the frequency of fusions within the banded class (Cowie \& Jones, 1998).

In making these comparisons, it was necessary to choose a method for measuring change in frequency and estimating selection. In the course of discussing the options, the local morph frequency differences were also analysed in more detail. The results of this finer-scale examination are considered here. 


\section{Materials and methods}

The survey and scoring methods are fully outlined by Cowie \& Jones (1998). All but four of the 157 Marlborough Downs sites of Cain \& Currey (1963a), including both $C$. nemoralis and $C$. hortensis sites, were identified. Snails were collected from as small an area as possible, usually less than $100 \mathrm{~m}^{2}$, although if they were sparse or if the original site was a larger area, collecting sites were sometimes expanded. Samples were scored as in the original survey, and only scores for adult individuals were analysed. Whenever samples were large enough to allow valid statistical testing to be carried out, the morph frequencies in samples from 1960-61 were compared with those from 1985.

The 'brown' area effect to the south of the Marlborough Downs involves a high frequency of browns compared to the adjacent areas. It was possible to compare frequencies of browns and non-browns in a total of 43 possible comparisons. Twenty-three sites showed a decrease in browns. Pooling all data from these 43 sites, a general decline in frequency of browns over the 25 intervening years was detected.

The generation time of C. nemoralis is between 3 years (Clarke \& Murray, 1962; Wolda, 1970; Murray \& Clarke, 1978) and 5 years (Wall et al., 1980). The interval between the two surveys therefore spans approximately eight to five generations. The method of calculating selective coefficients over several generations by treating the difference equation as an approximation to a differential equation and finding the integral goes back at least to Haldane (1924; summarized in Haldane, 1932). The problem is described by Clarke \& Murray (1962) as follows, when discussing change in frequency of the brown allele at the colour locus of $C$. nemoralis at another locality. After a round of random mating the population is represented by:

\begin{tabular}{|c|c|c|}
\hline Ger & $C^{B} C^{B}$ & $C^{B} C^{X}$ \\
\hline Fre & $\left(\begin{array}{ll}1 & q\end{array}\right)^{2}$ & $2 q(1 \quad q)$ \\
\hline Fit & $\left(\begin{array}{ll}1 & s\end{array}\right)$ & $(1$ \\
\hline
\end{tabular}

$C$ represents the ground colour locus, $B$ and $X$ the brown and the non-brown alleles. Over one generation the change in allele frequency is:

$$
\left.\Delta q=s q^{2}(1 \quad q) /\left[\begin{array}{lll}
1 & s(1 & q^{2}
\end{array}\right)\right]
$$

Comparison was made of three methods of estimating $s$, given an estimate of the initial frequency $q$ and the change in frequency.

\section{Method A, by integration}

If $q_{0}$ is the frequency of recessive alleles at the start, and $q_{n}$ is the frequency after $n$ generations and $s$ refers to the dominant morph, as above, then integrating $\Delta q$ provides (Clarke \& Murray, 1962):

$$
\begin{aligned}
& s\left[n+\ln \left(q_{n} / q_{0}\right) \quad 1 / q_{n}+1 / q_{0}\right] \\
& =\ln \left[q_{n}\left(1 \quad q_{0}\right) / q_{0}\left(\begin{array}{ll}
1 & q_{n}
\end{array}\right)\right] \quad 1 / q_{n}+1 / q_{0} .
\end{aligned}
$$

The selective coefficient $s$ may therefore be calculated assuming a given number $(n)$ of generations to have elapsed. Clarke \& Murray (1962) also provide the variance, which takes account of sample size. The estimate is an approximation which will be more accurate for frequencies near the centre of the range than for extreme frequencies, and for small selective coefficients. Manly (1985) provides a comprehensive account of the properties of this and related methods.

\section{Method B, from morph ratios}

An alternative method of calculating $s$ is described by Cain et al. (1990). The value of $1-s$ is estimated for an arbitrary time interval (1 year in their study) by saying that the ratio of morphs of the dominant allele to morphs of the recessive allele in 1 year is $1-s$ times the ratio in the previous time interval. This is true during the course of selection within one generation, and is a reasonable way of representing change when there are overlapping generations, but the pattern is modified by segregation of gametes. The method works over a range of frequencies and times for which the logarithm of frequency on time is more or less linear. If $P_{n}$ is the frequency of the dominant morph at time $n$ and $Q_{n}$ is the frequency of the recessive morph:

$P_{n+1} / Q_{n+1}=\left(\begin{array}{ll}1 & s\end{array}\right) P_{n} / Q_{n}$

Then for a pair of ratios with a gap of $n$ time units, fitness per unit time may be obtained from:

$$
\left(\begin{array}{ll}
1 & s
\end{array}\right)^{n}=P_{n} Q_{0} / P_{0} Q_{n} .
$$

The transition from discrete to continuous change is discussed by Cavalli (1950), and graphical treatment of allele frequency change using log transformation is employed extensively by Cavalli-Sforza \& Bodmer (1971). 


\section{Method C, by iteration}

These methods were developed some years ago when personal computers were not available. If fitness differences per generation are desired, the natural approach now would be to choose a value of $s$ which provides $q_{n}$, given $q_{0}$, by trial and error. This may be carried out simply by incrementing $s$ by small amounts until a suitable degree of agreement is reached or by use of a convergent algorithm. We have used the method of false positions (e.g. Fröberg, 1966). Let $y=q_{n}-q^{\prime}$, where $q^{\prime}$ is an estimate of $q_{n}$ found using a trial value of $s$. For two such values $y_{k-1}$ and $y_{\mathrm{k}}$, computed using two values $s_{k-1}$ and $s_{k}$, then so long as $s$ is reasonably close to the required value, a better value of $s$ is:

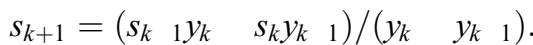

The $s$-value calculated by the integration method was used as the starting point for the convergence.

\section{Results}

Table 1 shows the three methods of estimating $s$ applied to the data on frequency of browns. It is assumed that eight generations have elapsed, because most ecological studies have indicated a generation time of about 3 years. There can be seen to be general agreement between the estimates, but in order to examine the relationship more closely, methods $\mathrm{A}$ and $\mathrm{B}$ have been plotted on method $\mathrm{C}$ in Fig. 1. Good linear relationships exist between $\mathrm{A}$ and $\mathrm{C}$ and between $\mathrm{B}$ and $\mathrm{C}$, except that samples 3 and 7 , which are among the samples with extreme frequencies, produce aberrant estimates of $s$. The diagonal shown is for unit slope, and the graphs both indicate steeper trends. Excluding samples 3 and 7 the reduced major axis estimate of slope is 1.30 for $\mathrm{A}$ on $\mathrm{C}$ and 1.05 for $\mathrm{B}$ on $\mathrm{C}$. The integration method therefore provides estimates some $30 \%$ larger than the iteration, whereas estimates by the ratio method are $5 \%$ larger. Further experimentation with a range of values of $q$ and $s$ chosen at random and different time intervals indicates that integration progressively overestimates $s$ as the absolute value of $s$ increases. The ratio method underestimates $s$ when $s$ is negative and works best for positive $s$ and frequencies of the dominant morph between about 10 and $70 \%$.

Using the estimates of standard error from method A in Table 1, we can test for significance of deviation from $s=0$ by calculating $\chi^{2}$ as $s^{2} / \operatorname{Var}(s)$. The sum of these values minus the $\chi^{2}$-value calculated from the sum is a measure of heterogeneity between samples. It is 113.5 , which is highly significant (d.f. $=42, P<0.001$ ). This is a conservative estimate of heterogeneity; the equivalent calculation based on the $2 \times 2$ contingency tables for each sample gives a value of 187.2. It is therefore legitimate to look for patterns of variation in the data. Figure 2 shows a diagram of the location of the sites. Those in which $s$ has a positive sign (brown at a disadvantage) are indicated as squares and those with a negative sign (brown at an advantage) as crosses. The grid shown is coded as in the grid of $1 \mathrm{~km}$ squares given in fig. 3 of Cain \& Currey (1963a). Over most of the area, sites where brown has increased are mixed with those in which it has decreased. There is, however, a band of 10 contiguous sites extending over $2 \mathrm{~km}$ in row $\mathrm{D}$, located on Rockley and Clatford Down, in which brown has decreased. It is possible that these indicate an area where the disadvantage of brown is particularly marked.

Spatial pattern is not quite independent of frequency, however, because brown is at a low frequency at Barbury Castle in square I4 and increases towards the highest values at Parson's Penning in C2 and B3. In order to find out whether frequency change is related to initial frequency, the difference between the successive brown morph frequencies was plotted on the initial value. The regression coefficient obtained was $-0.171 \pm 0.089$ (for comparison with zero slope, $t_{41}=1.93, P=0.06$ ). For small changes entirely independent of frequency, the expected slope would be zero, whereas the observed value is negative and nearly significant. In any sampling from starting values within a limited range where the succeeding samples are random variables within the same range a negative slope is to be expected; if both sets of values were random variables the expected slope would be -1 . A negative gradient may therefore suggest either random or selective convergence of extreme frequencies.

Brown is the morph that provides most data for comparison. Five-banded remains present at a very high frequency to the north, and there is a large area to the south that is almost entirely unbanded and mid-banded. Between the two is a stretch of land showing intermediate frequencies (Fig. 3). Cain \& Currey (1963a) divide it into two areas referred to as ' $\mathrm{B}$, the Barbury area (transitional)' and ' $\mathrm{D}$, the southern intermediate area'. This zone contains 16 sites for which both early and late samples are large enough for comparisons to be made. The average frequency of unbanded over the whole stretch did not change (31.9\% in the first survey, $32.2 \%$ in the second). Using contingency tables, however, the $\chi^{2}$ testing heterogeneity is 41.1 , which is significant (d.f. $=15, P<0.001$ ). This is largely because three samples on Maizey Down in square G6 have shown a decline in unbanded, whereas in samples to the northwest (squares I3, 4 and 5 and H6), unbanded has tended 
Table 1 Brown morph frequency in Cepaea nemoralis and selective coefficient of the brown morph for 43 sites on the Marlborough Downs sampled twice, with a 25 -year interval between samplings. It is assumed that eight generations have elapsed. Br1 and Br2, morph frequencies in 1961 and 1985; A, estimate of $s$ and its standard error by integration; B, estimate from morph ratios; $\mathrm{C}$, estimate by iteration

\begin{tabular}{|c|c|c|c|c|c|}
\hline Sample & $\mathrm{Br} 1$ & $\mathrm{Br} 2$ & $\mathrm{~A} \pm \mathrm{SE}$ & B & $\mathrm{C}$ \\
\hline 1 & 0.392 & 0.464 & $-0.044 \pm 0.065$ & -0.038 & -0.033 \\
\hline 2 & 0.277 & 0.085 & $0.179 \pm 0.064$ & 0.162 & 0.157 \\
\hline 3 & 0.957 & 0.714 & $0.371 \pm 0.151$ & 0.238 & 0.780 \\
\hline 4 & 0.870 & 0.649 & $0.212 \pm 0.075$ & 0.148 & 0.119 \\
\hline 5 & 0.457 & 0.522 & $-0.040 \pm 0.058$ & -0.033 & -0.028 \\
\hline 6 & 0.550 & 0.615 & $-0.044 \pm 0.062$ & -0.034 & -0.028 \\
\hline 7 & 0.742 & 0.889 & $-0.268 \pm 0.179$ & -0.136 & -0.090 \\
\hline 8 & 0.758 & 0.765 & $-0.008 \pm 0.096$ & -0.005 & -0.004 \\
\hline 9 & 0.250 & 0.380 & $-0.086 \pm 0.054$ & -0.079 & -0.071 \\
\hline 10 & 0.560 & 0.574 & $-0.009 \pm 0.051$ & -0.007 & -0.006 \\
\hline 11 & 0.585 & 0.535 & $0.031 \pm 0.055$ & 0.025 & 0.021 \\
\hline 12 & 0.414 & 0.467 & $-0.032 \pm 0.088$ & -0.027 & -0.024 \\
\hline 13 & 0.500 & 0.500 & $0.000 \pm 0.096$ & 0.000 & 0.000 \\
\hline 14 & 0.792 & 0.725 & $0.066 \pm 0.070$ & 0.044 & 0.034 \\
\hline 15 & 0.654 & 0.559 & $0.063 \pm 0.057$ & 0.049 & 0.041 \\
\hline 16 & 0.579 & 0.259 & $0.183 \pm 0.080$ & 0.157 & 0.145 \\
\hline 17 & 0.744 & 0.807 & $-0.075 \pm 0.065$ & -0.046 & -0.033 \\
\hline 18 & 0.633 & 0.684 & $-0.040 \pm 0.082$ & -0.029 & -0.023 \\
\hline 19 & 0.125 & 0.111 & $0.017 \pm 0.082$ & 0.017 & 0.016 \\
\hline 20 & 0.769 & 0.815 & $-0.058 \pm 0.096$ & -0.035 & -0.025 \\
\hline 21 & 0.731 & 0.686 & $0.037 \pm 0.063$ & 0.027 & 0.021 \\
\hline 22 & 0.425 & 0.228 & $0.122 \pm 0.044$ & 0.108 & 0.101 \\
\hline 23 & 0.733 & 0.385 & $0.208 \pm 0.056$ & 0.169 & 0.150 \\
\hline 24 & 0.085 & 0.051 & $0.068 \pm 0.087$ & 0.065 & 0.064 \\
\hline 25 & 0.280 & 0.003 & $0.616 \pm 0.124$ & 0.468 & 0.471 \\
\hline 26 & 0.075 & 0.218 & $-0.164 \pm 0.089$ & -0.167 & -0.159 \\
\hline 27 & 0.425 & 0.385 & $0.024 \pm 0.054$ & 0.021 & 0.018 \\
\hline 28 & 0.343 & 0.145 & $0.145 \pm 0.065$ & 0.131 & 0.125 \\
\hline 29 & 0.495 & 0.421 & $0.043 \pm 0.067$ & 0.036 & 0.032 \\
\hline 30 & 0.763 & 0.636 & $0.100 \pm 0.053$ & 0.073 & 0.058 \\
\hline 31 & 0.245 & 0.299 & $-0.037 \pm 0.053$ & -0.034 & -0.032 \\
\hline 32 & 0.704 & 0.707 & $-0.003 \pm 0.070$ & -0.002 & -0.001 \\
\hline 33 & 0.273 & 0.426 & $-0.099 \pm 0.050$ & -0.089 & -0.079 \\
\hline 34 & 0.683 & 0.577 & $0.072 \pm 0.060$ & 0.056 & 0.046 \\
\hline 35 & 0.469 & 0.320 & $0.087 \pm 0.066$ & 0.076 & 0.069 \\
\hline 36 & 0.336 & 0.490 & $-0.096 \pm 0.047$ & -0.084 & -0.072 \\
\hline 37 & 0.260 & 0.333 & $-0.049 \pm 0.072$ & -0.045 & -0.041 \\
\hline 38 & 0.314 & 0.154 & $0.120 \pm 0.106$ & 0.109 & 0.104 \\
\hline 39 & 0.254 & 0.385 & $-0.086 \pm 0.060$ & -0.079 & -0.071 \\
\hline 40 & 0.486 & 0.543 & $-0.036 \pm 0.050$ & -0.029 & -0.025 \\
\hline 41 & 0.216 & 0.194 & $0.018 \pm 0.052$ & 0.017 & 0.016 \\
\hline 42 & 0.528 & 0.429 & $0.058 \pm 0.110$ & 0.049 & 0.043 \\
\hline 43 & 0.471 & 0.444 & $0.015 \pm 0.101$ & 0.013 & 0.011 \\
\hline Means & & & 0.037 & 0.029 & 0.042 \\
\hline Total & 0.489 & 0.376 & $0.065 \pm 0.100$ & 0.056 & 0.050 \\
\hline
\end{tabular}

to increase. The cline between the two frequency patches may be relocating.

To the south of the transitional areas is one where samples are almost entirely unbanded or mid-banded.
Unbanded is dominant over five-banded at the banding locus, and an allele at an unlinked locus reduces the fivebanded phenotype to a single central band. This area is therefore almost fixed for mid-banded, and the frequency

(C) The Genetical Society of Great Britain, Heredity, 82, 336-342. 

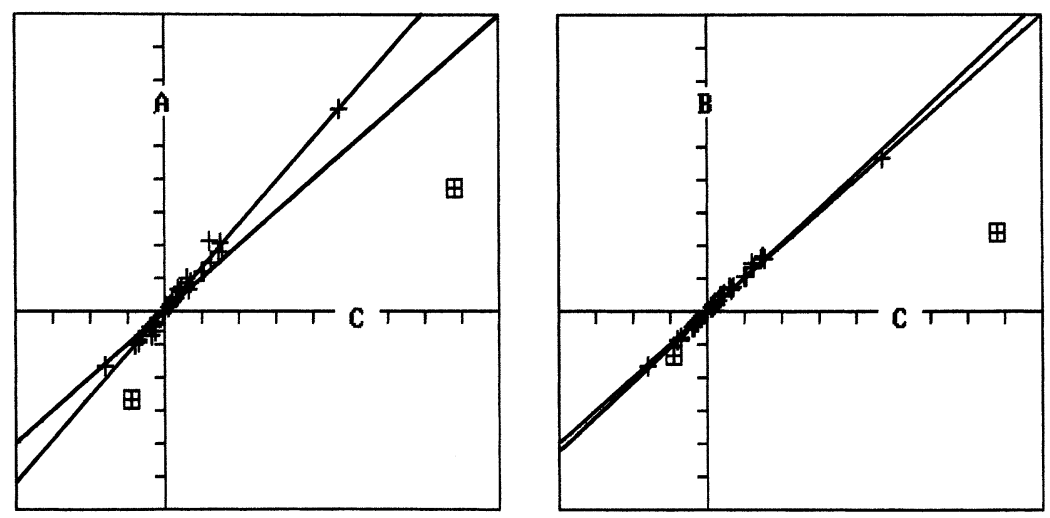

Fig. 1 Estimates of selection in Cepaea nemoralis using data on change in morph frequency in Table 1. Left, estimates by method A plotted on method C; right, method B plotted on method C. See text for description of methods. Diagonal line shows unit slope. Steeper lines are slopes of the reduced major axis when the exceptional values marked with boxes (samples 3 and 7) are excluded.

of unbanded may be examined as in the transitional area for the possibility of temporal change. Here, 42 samples are available for comparison. The heterogeneity of response is significant $\left(\chi_{41}^{2}=65.0, P \approx 0.01\right)$. If the four areas are taken together (63 samples), then the regression of change in frequency of unbanded on initial frequency is significantly negative $(b=-0.163$, $\left.t_{61}=2.07, P<0.05\right)$.

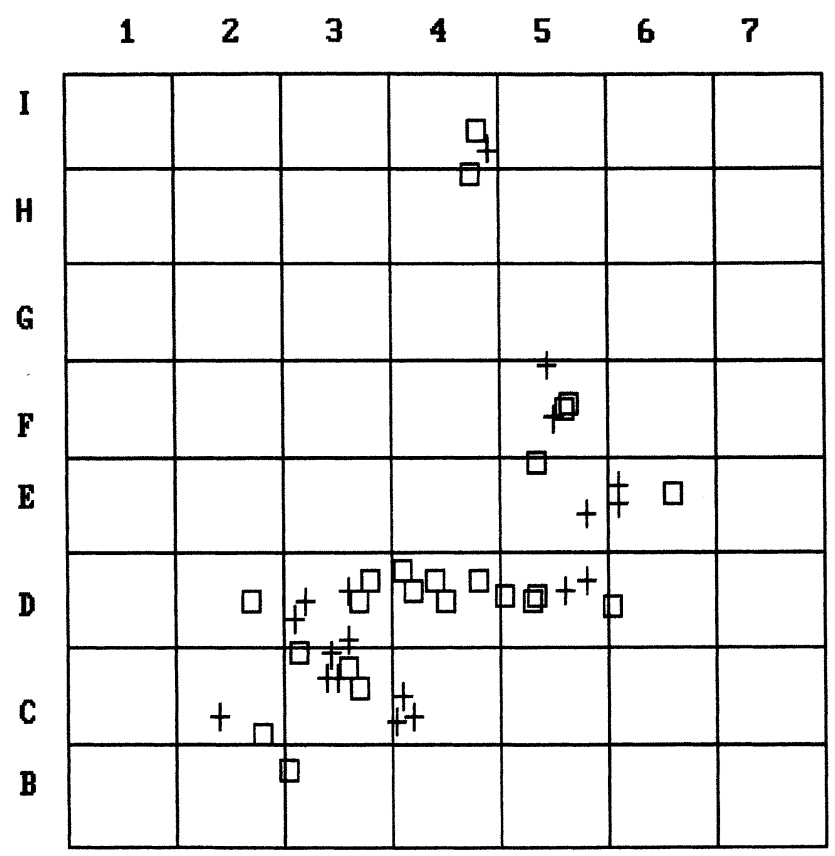

Fig. 2 Sites for which change in brown morph frequency in Cepaea nemoralis is recorded, arranged according to the $1 \mathrm{~km}$ grid given by Cain \& Currey (1963a). Squares, no change or decline of brown between surveys; crosses, increase in brown between surveys.

\section{Discussion}

Three methods have been used to calculate the selective coefficient of the brown morph in samples of C. nemoralis from the Marlborough Downs. Although one is a mathematical and another a pragmatic approximation, they perform so as to give estimates which are usually broadly comparable to those obtained by iteration over the interval concerned. The ratio method is set up to

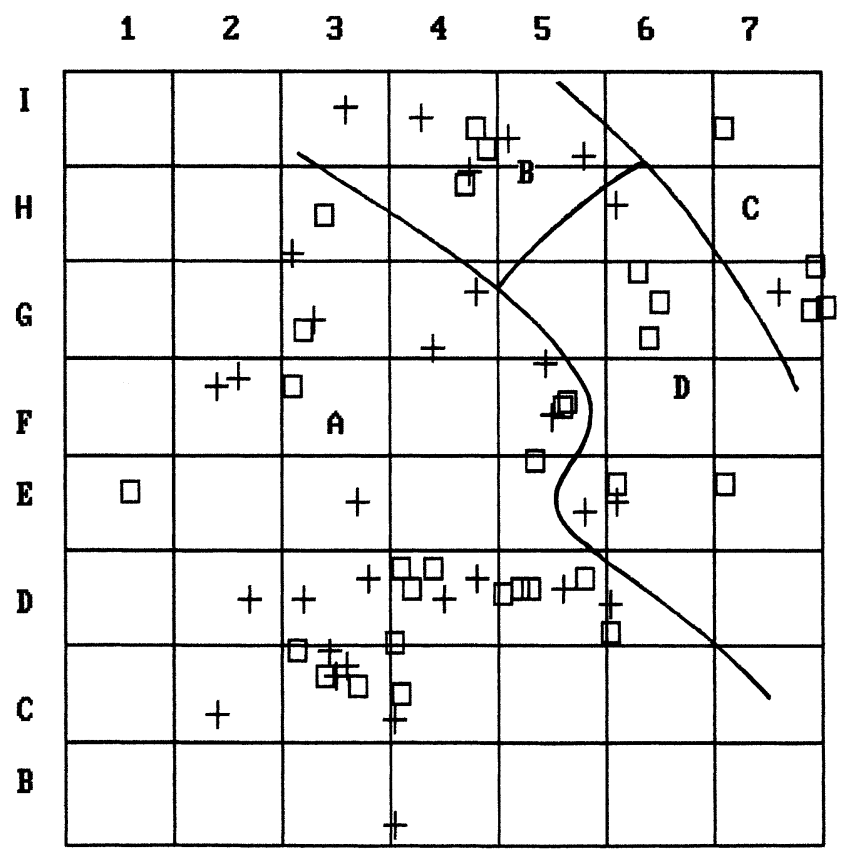

Fig. 3 Sites for which change in unbanded frequency in Cepaea nemoralis is recorded, arranged on the $1 \mathrm{~km}$ grid. Four regions labelled A-D were distinguished by Cain \& Currey (1963a). In area A samples contain unbanded and mid-banded, which is a phenotype homozygous for five-banded. Area C is almost entirely five-banded, and $\mathrm{B}$ and $\mathrm{D}$ are intermediate in frequency. Squares, no change or decline in unbanded; crosses, increase in unbanded between surveys.

(C) The Genetical Society of Great Britain, Heredity, 82, 336-342. 
give a direct estimate over any preferred time interval, not necessarily a generation. Assuming eight generations to have elapsed over the 25-year time interval, the average decline in frequency of browns is such as could be brought about by a selective disadvantage of $3-6 \%$ per generation.

Unfortunately, it is still not known what kind of selection may be operating. Difference in consistency and magnitude of change between the Rockley/Clatford Down region and elsewhere may indicate local variation in selection, but if so, it does not follow obvious differences in habitat. Overall, there is overwhelming evidence that selection influences morph frequencies in C. nemoralis (Clarke et al., 1978; Jones et al., 1978; Cook, 1998). Frequencies probably track habitat change brought about by climatic fluctuation and human activity. The response is slow, however, and with respect to the southern English downland populations, Cameron and colleagues have argued that introductions over the past few centuries have played an important part in establishing the present area effects (Cameron et al., 1977, 1980; Cameron \& Dillon, 1984; Cameron \& Pannett, 1985). Distinct patches of different frequencies could therefore be a result of relatively recent meeting of two or more spreading populations and may be disappearing as introgression takes place and as all the patches respond to similar large-scale selection pressures. The tendency to homogenization suggested by the present analysis may be evidence of this process. Over a longer term, if land-use patterns change again, Cepaea populations may vanish from the Downs altogether, or be subject to a new set of disturbances which change the morph frequencies before they have had a chance to become homogeneous or matched to selection pressures. New area effects could appear, with frequencies different from those we see now, and with different boundaries.

After intensive study for over half a century the extraordinary phenotypic variety in C. nemoralis is still not understood. The challenge should not be abandoned because the problem is difficult to unravel; it relates to a common class of polymorphisms. In field surveys, however, there is a risk of overexplaining data and finding support for hypotheses where none exists. To avoid this, Cowie \& Jones (1998) tested only hypotheses already set up, and with respect to browns concluded that a small general decline in frequency has taken place. In this paper we suggest that there may also be spatial variation in response and a homogenizing process of some kind. Support is not conclusive, but it is sometimes rewarding to follow suggestive leads. Instead of simply reporting that morph frequency did not relate to habitat on the Marlborough Downs, Cain \& Currey (1963a) used their data to develop the new concept of area effects. The result was a large body of work and discussion (e.g. Cain \& Currey, 1963b; Goodhart, 1963; Wright, 1965; Carter, 1968; Clarke, 1968; Gould \& Woodruff, 1990), which has stimulated new approaches to understanding the polymorphism.

Any abrupt transition may signal an area effect. Cain (1968) examined another on a sand dune in north Wales, at the same time wondering whether the term should be applied to so small an area as it occupied. This Welsh dune has recently been resurveyed (Cook \& Pettitt, 1998). In view of the disturbances known to have occurred in the interim, the present pattern suggests that whatever caused the discontinuity observed by Cain (1968), movement of individuals has since contributed to homogenization. The results for brown from the Marlborough Downs may be another case of migration leading to decay of accidentally generated discontinuities. If movement is responsible for breaking down pattern, it should act equally on all morphs. It is therefore noteworthy that similar patterns were observed in both brown and unbanded/five-banded frequencies. Repeat surveys, studies of allozyme variation and rates of colonization of new regions all suggest that passive movement may have a more important influence on morph frequency patterns than has previously been assumed (Cook, 1998; Cook \& Pettitt, 1998). If so, reassessment of the effects of migration may lead to a fresh view of the causes of polymorphism in Cepaea.

\section{References}

CAIN, A. J. 1968. Studies on Cepaea. V. Sand dune populations of Cepaea nemoralis (L.). Phil. Trans. R. Soc. B, 253, 499-517.

CAIN, A. J. AND Currey, J. D. 1963a. Area effects in Cepaea. Phil. Trans. R. Soc. B, 246, 1-81.

CAIN, A. J. AND CURREY, J. D. 1963b. The causes of area effects. Heredity, 18, 467-471.

CAIN, A. J., COOK, L. M. AND CURREY, J. D. 1990. Population size and morph frequency in a long-term study of Cepaea nemoralis. Proc. R. Soc. B, 240, 231-250.

CAMERON, R. A. D. AND DILlon, P. J. 1984. Habitat stability, population histories and patterns of variation in Cepaea. Malacologia, 25, 271-290.

CAMERON, R. A. D. AND PANNETT, D. J. 1985. Interaction between area effects and variation with habitat in Cepaea. Biol. J. Linn. Soc., 24, 365-379.

CAMERON, R. A. D., WILliAMSON, P. AND MORGAN-HUWS, D. I. 1977. The habitats of the land snail Cepaea nemoralis (L.) on downland and their ecological significance. Biol. J. Linn. Soc., 9, 231-241.

CAMERON, R. A. D., CARTER, M. A. AND PALleS-ClARK, M. A. 1980. Cepaea on Salisbury plain: patterns of variation, landscape history and habitat stability. Biol. J. Linn. Soc., 14, 335-358.

CARTER, M. A. 1968. Studies on Cepaea II. Area effects and visual selection in Cepaea nemoralis (L.) and Cepaea hortensis. Phil. Trans. R. Soc. B, 253, 397-446. 
CAVALLI, L. L. 1950. The analysis of selection curves. Biometrics, 6, 208-220.

CAVALLI-SFORZA, L. L. AND BODMER, w. F. 1971. The Genetics of Human Populations. W. H. Freeman \& Co., San Francisco.

ClARKE, B. C. 1968. Balanced polymorphism and regional differentiation in land snails. In: Drake, E. T. (ed.) Evolution and Environment, pp. 351-368. Yale University Press, New Haven, CT.

ClARKe, B. AND MURRAY, J. 1962. Changes of gene-frequency in Cepaea nemoralis (L.): the estimation of selective values. Heredity, 17, 467-476.

ClARKE, B., ARTHUR, W., HORSLEY, D. T. AND PARKIN, D. T. 1978. Genetic variation and natural selection in pulmonate snails. In: Fretter, V. and Peake, J. (eds) The Pulmonates, Vol. 2A. Systematics, Evolution and Ecology, pp. 220-270. Academic Press, New York.

COOK, L. M. 1998. A two-stage model for Cepaea polymorphism. Phil. Trans. R. Soc. B, 353, 1577-1593.

COOK, L. M. AND PETTITT, C. W. A. 1998. Morph frequencies in the snail Cepaea nemoralis: changes with time and their interpretation. Biol. J. Linn. Soc., 64, 137-150.

COWIE, R. H. AND JONES, J. S. 1998. Gene frequency changes in Cepaea snails on the Marlborough Downs over twenty-five years. Biol. J. Linn. Soc., 65, 233-255.

FRÖBERG, C.-E. 1966. Introduction to Numerical Analysis. Addison-Wesley, Reading, MA.
GOODHART, C. B. 1963. "Area effects" and non-adaptive variation between populations of Cepaea (Mollusca). Heredity, 18, 459-465.

GOULD, S. J. AND WOODRUFF, D. S. 1990. History as a cause of area effects: an illustration from Cerion on Great Inagua, Bahamas. Biol. J. Linn. Soc., 40, 67-98.

HALDANE, J. B. S. 1924. A mathematical theory of natural and artificial selection. Proc. Camb. Phil. Soc., 23, 19-41.

HALDANE, J. B. S. 1932. The Causes of Evolution. Longmans, London.

JONES, J. S., LEITH, B. H. AND RAWLingS, P. 1978. Polymorphism in Cepaea: a problem with too many solutions? Ann. Rev. Ecol. Syst., 8, 109-143.

MANLY, B. F. J. 1985. The Statistics of Natural Selection. Chapman \& Hall, London.

MURRAY, J. AND CLARKE, B. 1978. Changes in gene frequency in Cepaea nemoralis over fifty years. Malacologia, 17, 317-330.

WAll, S., CARTER, M. A. AND ClARKe, B. 1980. Temporal changes of gene frequencies in Cepaea hortensis. Biol. J. Linn. Soc., 14, 303-317.

wOLDA, H. 1970. Variation in growth-rate in the land snail Cepaea nemoralis. Res. Popul. Ecol., 12, 185-204.

WRIGHT, s. 1965. Factor interaction and linkage in evolution. Proc. R. Soc. B, 162, 80-104. 